\title{
AÇÕES EDUCATIVAS PROPOSITORAS PARA O ENSINO DA CULTURA
}

\section{AFRICANA}

Beloní Cacique Braga

ESEBA/UFU

caciquebeloni@ufu.br

Resumo: A proposta deste texto é compartilhar as ações educativas realizadas pela pesquisadora com discentes e docentes representantes de diferentes instituições que têm em comum o interesse pela cultura africana. Trata-se de um relato de experiência cujas ações e vivências ocorreram entre 2015-2017 impulsionadas pela realização do projeto de Formação de Professores no país do Mali/ África e que vem se expandindo também como processo formativo entre os educadores brasileiros. $O$ projeto se justifica pela constante necessidade de discussão da temática da cultura africana e para a ampliação dos conhecimentos sobre o tema. Diante da lei 10.639/03 que abarca o ensino da história e cultura afrobrasileira e africana percebemos a necessidade de estratégias e recursos para os professores realizarem o ensino e para que a população de forma geral compreenda a importância deste povo na formação da nação. Sendo assim, por ter vivenciado como professora voluntária um projeto de formação de professores em Bamako, Mali, por três edições, 2015/2017, e por organizar um acervo pessoal de fotos, tecidos, objetos e materiais sobre a cultura africana acredito ser oportuno socializar os conhecimentos construídos enquanto professora aprendiz nesse processo.

\section{Introdução}

\section{O caminho, a experiência, a viagem}

A necessidade de aproximação e conhecimento sobre a cultura africana é notória. Possibilitar aos alunos a compreensão da história de um povo que vem sendo silenciada há anos requer esforço, mesmo com a promulgação da lei 10.639/2003 que traz a obrigatoriedade do ensino da cultura africana e afro-brasileira os desafios são muitos. Nem sempre o simples fato de conhecer a lei nos traz a clareza do compromisso de que a escola é espaço formativo, e que no caso deste relato, a motivação se deu pela vivência e aproximação com a África, sua história e com a relação desta com a nossa cultura, com a nossa história. 
As ações formativas ou educativas muitas vezes surgem das experiências individuais ou até mesmo daquelas que envolvem pessoas com as quais convivemos. E nesta trama entre conhecer para aprender surge a oportunidade da ação voluntária para o continente africano.

Algumas ações que compõem este relato, sendo a primeira ação educativa indispensável neste processo que se constituiu de forma pessoal, particular de educar-se a si mesmo, experenciar para partilhar. Diante do desafio do um projeto percebi a necessidade de desapegar-me de conceitos e possíveis pré-conceitos a respeito da cultura africana. Tornou-se necessário definir um caminho ou forma de entrada para entendimento/conhecimento deste continente, pois esta se daria em um país de aspectos culturais bem distintos nossa cultura. Destacam se neste contexto a religião, as dificuldades socioeconômicas, os processos educativos e a organização da sociedade malinense.

O convite para participar do Projeto de Formação de Professores no país do Mali veio por meio da ONG Ministério Together, com sede em Belo Horizonte e que mantem diversos projetos de apoio e ajuda humanitária no Brasil e em outros países. Assim, o Projeto de Formação de Professores no Mali desenvolveu-se no triênio de 2015-2017 contando com três equipes de voluntários, sendo apenas a líder e eu, as pessoas que acompanharam as ações no período completo.

O desafio tornou-se em ampla aprendizagem sobre a cultura de um dos 54 países do continente africano, o Mali, sétimo maior país da África, cuja capital Bamako foi nosso ponto de apoio. Ele se localiza ao noroeste da África, na região subsaariana e, marcado pela religião muçulmana, tem costumes e características bem peculiares. Possui aproximadamente 13 milhões de habitantes que com mais de 40 dialetos e o francês como idioma oficial.

O Mali é um país rico por sua diversidade étnica e cultural. A coabitação se organiza muitas vezes num mesmo espaço geográfico, mas cada etnia maliana tem sua própria organização social, política, econômica e educativa. Cada uma dispõe de sua língua e de dialetos. Temos assim, bambaras, malingues, soninques, peúles, dogons, bozós, tuaregues, songhais, mouros, berberes, saracol[e, senufos, tucolores e ainda muitos outros grupos.( GASSE, 2009)

Considerando a dificuldade educacional, linguística e o analfabetismo, o projeto direcionou as ações para a formação de professores que tinham o francês como 
idioma de referência com disponibilidade de encontro conciliados com os períodos de férias dos voluntários já que as equipes eram formadas por professores e pedagogos que atuam nas escolas públicas e particulares brasileiras com calendário similar, fator que favoreceu a realização das viagens em outubro/15, julho/16 e julho/17.

A permanência no país se reduzia a sete dias para o trabalho de visitação, imersão e formação dos professores. Nas três edições ouvimos relatos dos professores, realizamos oficinas e palestras a fim de contribuir com a melhoria da educação local que possui hoje, $70 \%$ de analfabetos. Havia muito a ser feito em tempos e espaços previamente organizados e , por isso, mantivemos ao longo deste tempo contato com alguns professores nos interstícios das viagens. Conhecer a necessidade local e saber o que levar para a partilha, para construir com os professores, além das dificuldades com o idioma que a equipe não dominava eram alguns dos desafios que tínhamos enquanto nos preparávamos para a formação com os professores.

\section{O que trouxemos na bagagem}

Ainda não tínhamos a dimensão entre o que levávamos para formação e o que de fato colhíamos em cada novo encontro em solo desconhecido. No entanto, com o retorno das viagens trouxemos na bagagem objetos específicos da cultura local, materiais escolares, tecidos e vestimentas caraterísticas da cultura malinense. Tudo nos parecia inusitado. Diante da riqueza das experiências vividas no Mali e dos recursos trazidos optamos por compartilhar com todos aqueles que desejassem nos ouvir e ver. Iniciamos realizando exposições, palestras e ações que promovessem o conhecimento da cultura africana. Tais ações vieram de encontro com a necessidade de discutir propostas de aplicabilidade da lei 10.639/2003 na escola na qual atuo como docente. A lei prevê que as escolas brasileiras devem incluir no currículo o ensino sobre a cultura africana e afro-brasileira. Concomitante com o projeto voluntário realizamos estudos individuais para entender melhor as questões étnico-raciais, a história da África e da cultura afro-brasileira.

Neste processo investigativo encontramos pesquisas com abordagem das questões étnico-raciais como SILVA (2011), GOMES (2006, 2011, 2013) que demonstram a necessidade de discussão sobre as questões étnico raciais, a 
dificuldade para a implementação da lei nas escolas diante do desconhecimento do seu conteúdo histórico e de condições diversas para realização do trabalho. Há um grupo de pesquisadores, de pessoas envolvidos no Movimento Negro e movimentos sociais que lutam pela superação das desigualdades e do preconceito, que consideram a educação com um caminho para minimizar as desigualdades e traçar caminhos mais justos

Estes grupos partilham da concepção de que a escola é uma das instituições sociais, responsáveis pela construção de representações positivas dos afro-brasileiros e por uma educação que tenha o respeito à diversidade como parte de uma formação cidadã. (GOMES, 2011, p.41)

A escola é um ponto de partida. Então como tornar todas estas questões em ações viáveis? Como a escola pode contribuir nesta discussão? De que cultura africana estamos falando? Diante das leituras, estudos, reflexões, imersão na cultura do Mali e da vivência enquanto docente da educação básica, organizei as ações apresentadas neste texto que foram surgindo a partir dos diálogos com as pessoas, as imagens, os objetos e os espaços, no Brasil e no Mali. Compreender a cultura africana, de certa forma, nos ajuda a pensar as nossas raízes e nos aponta para a forma como nos constituímos como um povo fortemente influenciados pelos africanos e por sua cultura.

Antes mesmo de pensar em propor ações fui convidada a dialogar com os alunos dos $7^{\circ} \mathrm{S}$ anos sobre o filme "O aluno - lição de vida"12, exibido pela profa de Geografia da ESEBA, Ínia Novaes, no projeto Sétima na sexta. Projeto que se propõe a exibir filmes que abordam também a cultura africana. Na roda de conversa na qual tentava responder o eu trouxe na minha bagagem após a viagem me dei conta da riqueza que trouxe dentro de mim após o convívio com este povo.

A primeira ação educativa realizada foi a exposição "África em tecidos e fotos" organizada no período de 12 a 29 de abril/2016, no espaço interno da ESEBA ${ }^{2}$ Escola de Educação Básica onde a pesquisadora atua como docente da Alfabetização Inicial com o intuito de expor a comunidade local as primeiras impressões e imagens

\footnotetext{
1 O filme se passa no Quênia e conta a história de um senhor de idade que desejava aprender a ler.

${ }^{2}$ A ESEBA-UFU é um Colégio de Aplicação da Universidade Federal de Uberlândia que atende aproximadamente 900 alunos da Ed. Infantil ao $9^{\circ}$ ano, além do Proeja.
} 
trazidas do Mali. Para orientar esta exposição os docentes das turmas de $1^{\circ} \mathrm{S}$ aos $3^{\circ} \mathrm{S}$ anos receberam um material com indicações de "ações educativas" para desenvolver com seus alunos, de forma a promover a compreensão de toda a exposição. O texto deste material sugeria possibilidades e estratégias de trabalho.

\begin{abstract}
A exposição África em tecidos e fotos tem como objetivo compartilhar com a comunidade a experiência vivida pela docente em viagem realizada como propósito de oferecer Formação Continuada aos professores cristãos na cidade de Bamako. Neste processo de construção dos espaços e formas de socialização percebemos a riqueza em conhecer uma cultura tão diferente. Assim, apresentamos a exposição com o intuito de ampliar nossos olhares para o continente africano e suas possibilidades. (material educativo)
\end{abstract}

Durante o período da exposição dialogamos com as pessoas que curiosamente desejavam entender mais sobre o Mali, especificamente sobre as imagens fotográficas expostas. Também foi possível realizar com a turma de $3^{\circ}$ ano, no qual atuava regente todas as ações propostas no Material Educativo. A exposição alcançou visibilidade na escola e na mídia local ganhando espaços de mais diálogos para além do local planejado.

Procurando ampliar a experiência e as discussões para a comunidade, para a cidade, para as demais escolas, realizamos uma segunda exposição "Bamako-África: olhar de professora aprendiz" realizada na Casa de Cultura Graça do Aché em Uberlândia, no período de 12 a 30 de setembro/ 2016, abrindo o espaço para receber escolas interessadas para a visitação. Contamos com a parceria da DICULT-UFU Diretoria de Cultura - UFU o Polo Arte na Escola para viabilizar a proposta. No evento de abertura foram convidados os alunos da ESEBA e a comunidade por meio da divulgação da mídia e no site da UFU. Nesta ocasião recebemos para a abertura diversas pessoas interessadas na temática e curiosas por entender sobre a África.

Recebemos três escolas públicas para visitação e ação educativa específica durante a semana com o acompanhamento de profissionais do Polo Arte na Escola e da professora proponente da exposição. Foram organizados três espaços: no primeiro haviam fotografias, objetos e tecidos; no segundo estruturamos um espaço com a exibição de vídeos feitos pela pesquisadora/viajante pelo Mali e no terceiro tínhamos um espaço para que as crianças realizassem desenhos a respeito da exposição em papéis contínuos afixados no chão. Em todos estes espaços havia a mediação e a 
conversa a respeito da cultura africana e sobre quais eram as impressões dos visitantes.

A divulgação das exposições e as entrevistas realizadas pela mídia local despertaram nos educadores o desejo de conhecer um pouco mais sobre a África e assim foram surgindo oportunidades de palestras e encontros. Realizamos encontros com graduandos do curso de Pedagogia da UFU para discutir sobre a temática de forma a tecer conversas sobre a cultura, os costumes, o currículo, além de responder às diversas curiosidades sobre este instigante continente.

As conversas se estenderam para duas escolas estaduais. Realizamos palestra para os alunos dos $7^{\circ} \mathrm{S}$ anos da EE Alice Paes e no encontro de formação continuada de professores da EE Padre Mario Florestan. Em ambos os espaços o início abordávamos sobre as viagens e o voluntariado e depois para a motivação dos grupos, sendo que na formação de professores ampliamos a discussão para desafiar os docentes para agregar em suas aulas discussões sobre as questões de acordo com as faixas etárias que trabalhavam.

No diálogo com os professores percebemos a necessidade de ter recursos didáticos e materiais para favorecer o ensino. Organizamos a proposta da Oficina Troca Trança, em 20/02/2017, com o objetivo de compartilhar com os participantes sobre a beleza e o cabelo na cultura malinense e as possibilidades de diálogos estabelecidos na formação de professores em Bamako. A oficina foi oferecida aos educadores da comunidade e tivemos a participação de seis professoras da educação básica da rede pública. Abordamos as questões sobre a cultura com o enfoque no cabelo africano a partir da vivência com as mulheres e meninas no Mali. Cada participante recebeu uma boneca de pano negra com o desafio de trançar seus cabelos e depois utilizar os enfeites e miçangas trazidos de Bamako. Vivência rica de sentimentos e aproximações com a abordagem da importância do cabelo pelo olhar da cultura africana e da cultura afro-brasileira.

Até este tempo as ações que se constituíram em expositivas e dialógicas com docentes, o que nos fez pensar sobre a necessidade de agir de forma direta com grupos de crianças, de forma pontual, para percebermos se as propostas educativas ganhariam força nos espaços de educação formal. Pensar a educação brasileira nos remetia ao contexto africano e a constatação de carências no sentido da organização 
do trabalho pedagógico, na formação de professores, de materiais didáticos e de incentivo a leitura. Por outro lado, percebemos a riqueza da cultura e da história de vida dos professores e das crianças malinenses.

Refletindo sobre estas questões surgiu a ideia de agregar um novo elemento para dialogar com a cultura africana. Produzimos a escrita de um livro infantil por considerar a importância da literatura na formação das crianças, conforme ressalta Maria (2011)

Assim, quanto maior for a imersão da criança em situações de linguagem maior for o número de palavras dirigidas a ela em seus primeiros anos de vida, quanto maior for o número de histórias lidas para ela, maior será sua facilidade de aprender a língua oral e, posteriormente, para dominar a língua escrita. (MARIA.2011, p.76)

Entendemos que a aprendizagem construída em um contexto rico desde a infância possibilitará saberes experienciais que constituirão como elementos da vida das crianças. Inspirados nesta proposição escrevemos uma história que de forma simples, que relata o caminho percorrido por uma criança africana moradora em uma aldeia até chegar a sua escola. Acompanhada pela mãe e pelo irmão, ainda bebê, a pequena Alimatá4 questiona sobre alguns costumes do seu povo e sobre o modo de vida na aldeia. A mãe conversa com ela ao longo do caminho. Costumes do povo africano são registrados no livro, que se apresenta com uma ilustração de linhas simples e com fundo/paisagem representado por tecidos africanos. O livro foi estruturado com pistas a respeito da cultura e durante sua leitura, geralmente, surgem novas perguntas propositoras de mais diálogo e novos saberes. Ao disponibilizarmos a leitura abrimos caminhos para encurtar as distâncias e promover aprendizagens significativas. Com o livro "A pequena Alimatá"3 agregamos mais possibilidades que favoreciam a educação das nossas crianças.

Por considerar a educação um caminho viável para a mudança de concepções sobre os modos de ver o mundo e sobre a formação de uma geração mais respeitosa com o outro, mais flexível as inovações e as diferenças definimos a realização de ações pontuais com crianças de diferentes escolas e projetos.

3 O livro infantil "A pequena Alimatá" foi escrito e publicado de forma independente para ser distribuído em algumas escolas de Bamako e atualmente vem e sendo comercializado no Brasil pela própria autora. 
Desde muito cedo, podemos aprender e conhecer diferentes realidades e compreender que a experiência social do mundo é muito maior do que a nossa experiência local, e que esse mesmo mundo é constituído e formado por civilizações, histórias, grupos sociais e etnias ou raças diversas. É também bem cedo em sua formação que as crianças podem ser reeducadas a lidar com os preconceitos aprendidos no ambiente familiar e nas relações sociais mais amplas. (BRASIL,2014. pág.14)

Seguindo esta concepção de educação realizamos uma proposta com atividades interligadas para uma turma de $1^{\circ}$ ano do Colégio Batista, instituição particular de Uberlândia, que iniciava um projeto sobre a África. Realizamos a contação da história "A pequena Alimatá", o diálogo sobre o Mali e a confecção das bonecas de tecidos e nós: as abayomis. Estas bonecas, segundo registros informais, representam o cuidado das mães africanas nos navios negreiros que ao ter suas crianças cansadas e agitadas pela viagem, rasgavam a barra de seus vestidos e com retalhos construíam bonecas amarradas com nós, servindo de acalento e brinquedo para os pequenos.

A realização deste encontro com este grupo de crianças se mostrou rico em diálogo e a participação se deu de forma proveitosa servindo para considerarmos que estas ações de forma conjunta seriam viáveis para novas turmas e escolas. O movimento da confecção das abayomis se tornou assim um marco ao final das palestras já realizadas e em momentos organizados na ESEBA juntamente com os demais docentes da instituição e com os pais dos alunos em encontros aos sábados.

Como fonte inesgotável de desejos e saberes a temática sobre a África encontrou acolhida em outros estados após a comercialização do livro "A pequena Alimatá". Na cidade de Francisco Morato a professora da educação infantil Lidiane Loiola realizou em suas aulas de arte a contação da história e propôs um desenho com composição de imagem utilizando a personagem. Em Niterói, a professora Patrícia Regina também realizou a contação da história, mas para alunos do $8^{\circ}$ ano de uma instituição particular que se encantaram com os tecidos africanos e propuseram a criação de estamparia africana em papel.

Enquanto isso, no segmento da Educação Infantil da ESEBA, espaço de vivência das múltiplas linguagens artísticas e culturais chamado de "Espaço Cultural", o professor Johnatan Alves introduziu o tema utilizando os tecidos africanos para a 
vivência do brincar e para descobrir a origem dos panos/tecidos. Desencadeou assim uma riqueza de ações internas relacionadas ao tecido, as cores, aos desenhos, ao brincar, a música e a cor da pele que constarão em relato de experiência do professor a ser divulgado pelo mesmo.

Ao mapear as ações realizadas neste triênio, 2015-2017, torna-se perceptível que foram muitos os parceiros desta jornada e que os desdobramentos são diversos não sendo possível neste tempo delinear a abrangência do projeto. O nosso desejo é de que sejam ações contagiantes de muitas outras e que o retorno ao Mali se dê de forma mais estruturada e sistêmica.

\section{CONSIDERAÇÕES FINAIS}

Por transitar no espaço da ESEBA cotidianamente tivemos a possibilidade de desenvolver as ações mencionadas em outros espaços agregando a contação de história e os registros das crianças sobre as suas impressões diante desde contexto africano.

O relato se compõe de muitos outros sentidos que o texto não comporta. $A$ curiosidade de todos aqueles que ouvem falar sobre a África que conheci se desdobra em novos questionamentos e ações que não terminam com estas linhas, porque enquanto registramos estas, já existem novas ações em andamento não divulgadas por não terem sido finalizadas.

Imagino que assim se dão todas as coisas que se relacionam a este rico continente e esta cultura inesgotável, desconhecida por alguns que de forma preconceituosa ou estereotipada, acreditam que o povo africano é pobre e não tem muito a oferecer. De fato, se encontram empobrecidos após processo exploratório e de escravidão que historicamente sofreram. Mesmo diante de tudo isso possuem uma riqueza inesgotável de vida criativa e de luta.

Acreditamos que mais aprendemos que ensinamos aos professores africanos, por isso, tornou-se importante compartilhar o vivido. As ações educativas realizadas após as viagens se constituíram de forma a abranger desde a formação docente, a contemplação artística e a vivência cultural, como a produção de material didático e a promoção de discussões sobre o ensino da cultura africana. São ações iniciais que se 
direcionam para contribuir também com a aplicabilidade de lei 10639/2003, mas que seguem para além disso.

Findamos o texto com o desafio de não finalizarmos as ações. $E$ que continuemos as proposições para construirmos novos saberes e significados sobre o que discorremos até aqui, conscientes de que assim seguimos na compreensão da nossa própria cultura.

"Eu não nasci na África, mas ela nasceu em mim."

\section{Referências bibliográficas}

BRAGA, Beloní Cacique. A pequena Alimatá. Uberlândia: Hebrom Editora. 2017.16p. BRASIL. Ministério da Educação. Secretaria de Educação Continuada, Alfabetização, Diversidade e Inclusão. História e cultura africana e afro-brasileira na educação infantil. Ministério da Educação. Secretaria de Educação Continuada, Alfabetização, Diversidade e Inclusão. -- Brasília: MEC/SECADI, UFSCar, 2014. 144 p.; il. , Ministério da Educação. Diretrizes Curriculares Nacionais para a Educação das Relações Étnico-Raciais e para o Ensino de História e Cultura AfroBrasileira e Africana. Parecer CNE/CP3/2004, 10 de março de 2004.

Plano Nacional de Implementação das Diretrizes Nacionais para a Educação das Relações Étnico-Raciais e para o Ensino de História e Cultura Afro-Brasileira e Africana. Ministério da Educação. Ministério da Secretaria Especial de Políticas de Promoção da Igualdade Racial/DF, 2009.

FERNANDES, Direly. O que você sabe sobre a África: uma viagem pela história do continente e dos afro-brasileiros. Rio de Janeiro: Nova Fronteira, 2016.

GASSES, Stéphanie. Inclusão versus exclusão escolar. As estratégias de luta contra o analfabetismo no Mali. Disponível em < http://www.epublicacoes.uerj.br/index.php/revistateias/article/view/24065> acesso em 08 out 2017.

GOMES, Nilma Lino. Diversidade étnico-racial: por um projeto educativoemancipatório. p.39-59.IN: Relações étnico-raciais e educação no Brasil. FONSECA, Marcus Vinícius; SILVA, Carolina Mostaro Neves da; FERNANDES, Alexandra Borges. Orgs. Belo Horizonte: Mazza Edições, 2011.

LIMA, Heloisa Pires. Histórias da Preta. São Paulo: Companhia das Letrinhas, 2005. 
MUNANGA, Kabengele; GOMES, Nilma Lino. O negro no Brasil de hoje. São Paulo: Global.2006

MARIA, Luiza de. Eduquemos para a leitura e as crianças aprenderão a ler “sozinhas". IN: ZACCUR, Edwiges. Alfabetização e letramento - o que muda quando muda o nome? Rio de Janeiro: Rovelle, 2011. págs 69-90. 